\title{
Promoting the Quality of Chinese Higher Vocational Education by General Education
}

\author{
Yongbo Lai ${ }^{1,2}$, Hongyao $\mathrm{Ni}^{3,4}$ \\ ${ }^{1}$ Department of Electrical Engineering, Jiangsu College of Information Technology, Wuxi, China \\ ${ }^{2}$ College of Science and Engineering, City University of Hong Kong, Kowloon, HongKong, China \\ ${ }^{3}$ Department of Business, Nantong Textile Vocational Technology College, Nantong, China \\ ${ }^{4}$ Department of Decision Sciences \& Managerial Economics, Chinese University of Hong Kong, \\ Shatin, HongKong, China \\ Email: yongbo100@sina.com, hyni@nttec.edu.cn
}

Received September 20 ${ }^{\text {th }}$, 2012; revised October 24 ${ }^{\text {th }}$, 2012; accepted November $2^{\text {nd }}, 2012$

\begin{abstract}
Due to the quality lack of Chinese higher vocational education, this paper analyzes the quality of the higher vocational education, from the point of dominant and recessive qualities of cultivating talents respectively. Based on the present situation of vocational education, this paper puts forward to apply the general education of international advanced universities, to improve the quality of education, moreover, proposed practical ways to implement intrinsic quality development of higher vocational education in China.
\end{abstract}

Keywords: Higher Vocational Education; Dominant Quality; Recessive Quality; General Education

\section{Introduction}

Chinese higher vocational education (CHVE) fits the social needs as its mission, goes the work-learning process, runs the way of school-enterprise cooperation, cultivates talents of high technical abilities as its goal, for the basic posts of production, construction, service and management. In order to achieve the abilities of posts, CHVE designs the knowledge, quality structure and training programs of cultivating students, pays attention to the practical training. The graduates directly have working abilities, meanwhile, training relevant professional skills and standards of the labor and social security departments. By examining and identifying the vocational skills, the graduate can get the corresponding degree certificates and occupational qualifications (Ministry of Education of China, 2010).

Under the guidance of the aforementioned CHVE policies, in the past 10 years, CHVE has made great achievements for the development speed, effect and large scale of operating schools in the world. But today, in the global information and international economic development uncertain times, the graduate are weak in thinking, solving problems, team working, communicating, and dedicating spirit quality abilities, which cause graduates hard to hunt a good job and enterprises difficult to find talented people, although China is a manufacturing and service industry powerful country. In the knowledge driven economy era, the whole society requirements shift from the post skills of higher vocational education oriented to the comprehensive quality requirements (Lai \& Wei, 2011). Except for skills, the graduate should have a noble personality, social responsibility, and make a living of wisdom in the society, all that is what general education (GE) pursues goals. In the GE mode, the curriculum designed for specialized technology and skills, moreover, it improves the learners understanding of the life and social values, as well as other relevant dedicating spirit (Schneider, 2012).
From the international GE and universities curriculum reform practicing experience, comprehensive development of people-oriented, which is an inevitable choice for universities curriculum reform, also represents the quality education's practice road for CHVE.

\section{Quality Education}

The quality education of CHVE is a kind of excellent persons' initiative activity, which obtained by the long time of study-forming, finally changes into comprehensive professional quality at the workplace, based on the professional quality of the inner regulations and requirements, which contains professional ethics, skills, behaviors, styles and consciousness, etc.

According to the student integrated embodiment and initiatives at the operating post, the professional quality education can be broken down into two parts: dominant quality and recessive quality education.

\section{Dominant Professional Quality Education}

The dominant professional quality education of CHVE consists in acquired skills of the graduate, which is dominant; this quality can be obtained by training in the process of teaching, and specifically-based on the school-enterprise cooperation, union industrial technical experts and school staffs, it aims to the social professional posts to make the talent training schemes, to develop courses, and according to the educational system layout to implement the teaching process (Lai, 2010). At present, CHVE gets used to teaching and training in the school's classroom for two years, adding post practice in the cooperating enterprises for one year, which is named " $2+1$ " cultivating mode. In view of the different skills requirements, normally it takes vocational schools about 1600 - 2000 unit teaching times to finish a total cultivating process.

Through that process, learning and training, the student can 
obtain knowledge and skills of professional quality, appropriate to the post of manufacturing, service, management and maintenance, etc. This kind of quality belongs to the external dominant professional quality, it can be proved through the various degree certificates, vocational certificates, or through the professional test to verify, and it is easy to quantify, to evaluate, and easy to obtain the skills further improvement in the limited training time at workplace.

\section{Recessive Professional Quality Education}

The recessive professional quality education of CHVE consists in obtaining professional ethics, working attitude, psychological anti-frustration, team spirit, moral sentiment, well state of mind, independent abilities of life and work style, etc. (Jiao \& Lai, 2010).

This quality belongs to the nature of a person, with recessive characteristics, not can be quantified, difficult to evaluate, it would be difficult to get the recessive quality improvement in the limited time, even if carried out teaching and training. Moreover, the cultivating process cannot be accomplished by one side alone of colleges, students and social enterprises, which need the three parties cooperating with each other for long time. At present, the major student of CHVE is of lowest graduated qualifications, which come from the remainders after the undergraduate education enrollment. In addition, as the student come from the single-child family growth environment, generally speaking, they have recessive common-mental fickleness, seeking quick success and instant benefits, self constraint deficiency, strong individual dependence in teamwork, poor flexibility, lacking of dedicating spirit, effective interpersonal exchanges and other professional quality.

The current CHVE mode, which widespread offers the course of political education, legal basis, entrepreneurial and employment ideological guidance, Meanwhile, the CHVE inculcates professional norms in curriculum and post training, practice the recessive professional quality education. Feedback from employment information and overall evaluation, it is difficult to meet the requirement levels in the quality of personnel cultivating.

\section{Mutual Relationship}

The relationship between the dominant quality and recessive quality, the dominant quality is the external performance of recessive quality, and the recessive is dominant quality's internal driving force. Also in the study of the relationship, the domestic and foreign scholars imaged it as the "iceberg theory" (Nielsen, 2002), that is the dominant quality skills of CHVE accounts for only one-eighth of the entire professional quality, and the recessive quality accounts for seven-eighths as the hidden underwater part of the immersed iceberg. The magnificent and ordinary life of the whole career is supported and promoted to progress by the recessive professional quality.

From the quality education of the characteristic and relationship, it can be concluded that the higher vocational education should be positive and effective developing recessive quality education for students and lay a solid foundation for broad career.

\section{General Education and Practice}

\section{General Education}

The GE is not only a kind of idea of the universities, also a kind of talent training mode (Schneider, 2012). It is the mainstream of international academic curriculum reform, has been practiced for many years in the United States, and aims to give students a broad humanities, arts, and scientific technology subject, to cultivate the basic important intelligence and as a citizen of social practice abilities; the mission of GE is developing the student-oriented, namely, having broad vision, liberal spirit and graceful feeling, and is not just a talented person with specialization of narrow field. In the GE mode, the student need have comprehensive understanding about the professional knowledge in the field of workplace, way of thinking, developing trend of history and master study methods, have a solid professional foundation and the rational knowledge and ability structure, at the same time, they can understand the important value orientation of contemporary society, develop the comprehensive personal quality and have a broad knowledge view (Van Dijk, 2001; Chen, 2006).

Based on the GE idea, the Hong Kong higher education " $3+$ $3+4$ " reform aims to help students develop a broad basic knowledge and skills to deal with new challenges in the 21st century globalization and increasingly complex social environment. In September 2012, the university in Hong Kong will enter new 4-year curriculum, according to the university strategy plans one after another which started from 2005-2006, the proposed vision as the foundation and according to the past experience, the university meet the new century to design, launch the new 4-year curriculum, carry out the reform of higher education in Hong Kong in concepts and innovation teaching methods. In the past several years almost all the university staffs participated in the work. The hardest challenge to the new thinking is to reconstruct the new curriculum design. The basic principle of design and management courses is the outcome-based approaches for this teaching reform (Leon, Mann, \& Pirola-Merlo, 2001). The new curriculum aims to let the students share a series of common learning experience, from the core courses to learn experience summary. The important element of the new curriculum will be more comprehensive in training students' generic skills and pluralistic thinking; No matter majoring in what subjects that the college graduate should be to have some skills and qualities, look for a universal value, blend arts and science together focusing on general, also make students have democratic social needed moral and citizen consciousness, be helpful for personal growth and development (Lai, 2010).

In the vocational transforming very frequent age, the GE mode can train professional broad caliber talents, whom shift more flexible at work. As the pre-President of Chinese university of Hong Kong said "general education is key to teach students how to self-study, ego growth, and now the world change very fast, perhaps the teaching object would not be useful in a few years later, tomorrow some industries might not exist, therefore we want our students to possess some broad vision, so that we can cope with changes soon after in the world”.

On the present situation, it is necessary and urgent that the CHVE should reform colleges' curriculum to promote the quality of education by GE model.

\section{Practical Ways}

CHVE has generally adopted the method of working process of the German higher vocational education, in the career oriented, which puts forward "obtain information, guidance plan, 
practice plan, evaluate program” four phases of teaching process (European Commission, 2008). The national vocational education research center of U.S.A, pays attention to professional education of scientific researching and innovating, the department of labor proposed "reasonable resources control, interpersonal, information access, systematic comprehensive analysis, multi-technology application” five abilities, including "skills, thinking, conducting" three kinds of qualities (Wilson, 2010), all this fully display the value of GE in the new century; The GE first concerns a person's comprehensive quality education, then to cultivate student as a professional people (Schneider, 2012); Comparing with GE, the CHVE focuses on the latter, even though the graduate have expertise and specialize in technology and skills, but lack of in intelligence, moral sentiment, character in all aspects for coordinating and full development, resulting in the current CHVE mode. As a professional people, who is insufficient in thinking and good at inquiry and solving the question's abilities, and could not active and effective participate in social and public affairs, it is weak as a social sense of responsibility of citizen consciousness.

Education is general and constant, teaching development needs to accord with person's growth roads (Soto, 2010). Today, teaching reform, research and practice can't separate the history and international environment, and need a lot of localization for the CHVE innovation.

The current CHVE operating mechanism is common implemented by colleges uniting enterprises and society for personnel training. Refereeing the general education concepts to improve the quality of CHVE, it should be integrated the enterprise culture and professional quality into the student's practice training, and regularly carried out the spirit of enterprise culture studying by the teachers and the enterprise personnel departments or public relations departments, such as small team workshops, skills contests, skills model selection and commending meetings, cultivating students professional spirit, team spirit and so on.

For the school curricula, the CHVE should add some courses of humanities, social science, information science, interdisciplinary, and be offered as compulsory courses; The CHVE should focus on cultivating the students' interpersonal and analyzing the social problems abilities, shape theirs social responsibilities. For example, a kind of practical training model is given as Table 1 for the quality education of CHVE.

Nowadays, under an environment of economic information and globalization, the effective time management is an essential ability to complete post tasks, to control life rhythm, to make good use of time, to work towards goals and not to consume energy (Lai, 2010). It is difficult to foster the aforementioned qualities in the current CHVE model. In view of the general education concepts, the popular science and general curriculum may be offered as elective courses, pay attention to enriching students professional and knowledgeable horizon, that is, the student can be mutual preliminary understanding different subjects knowledge, think a problem from a more open mind and multi-disciplinary perspectives.

For the social needs in China, the CHVE number of majors increases every year, it is numerous that there are 14,000 or so in 2011(Ministry of Education of China, 2010). There is no past experience to refer in developing popular science general curricula, so the CHVE staff should work hard to exploit them.

Table 1.

A kind of practical training model.

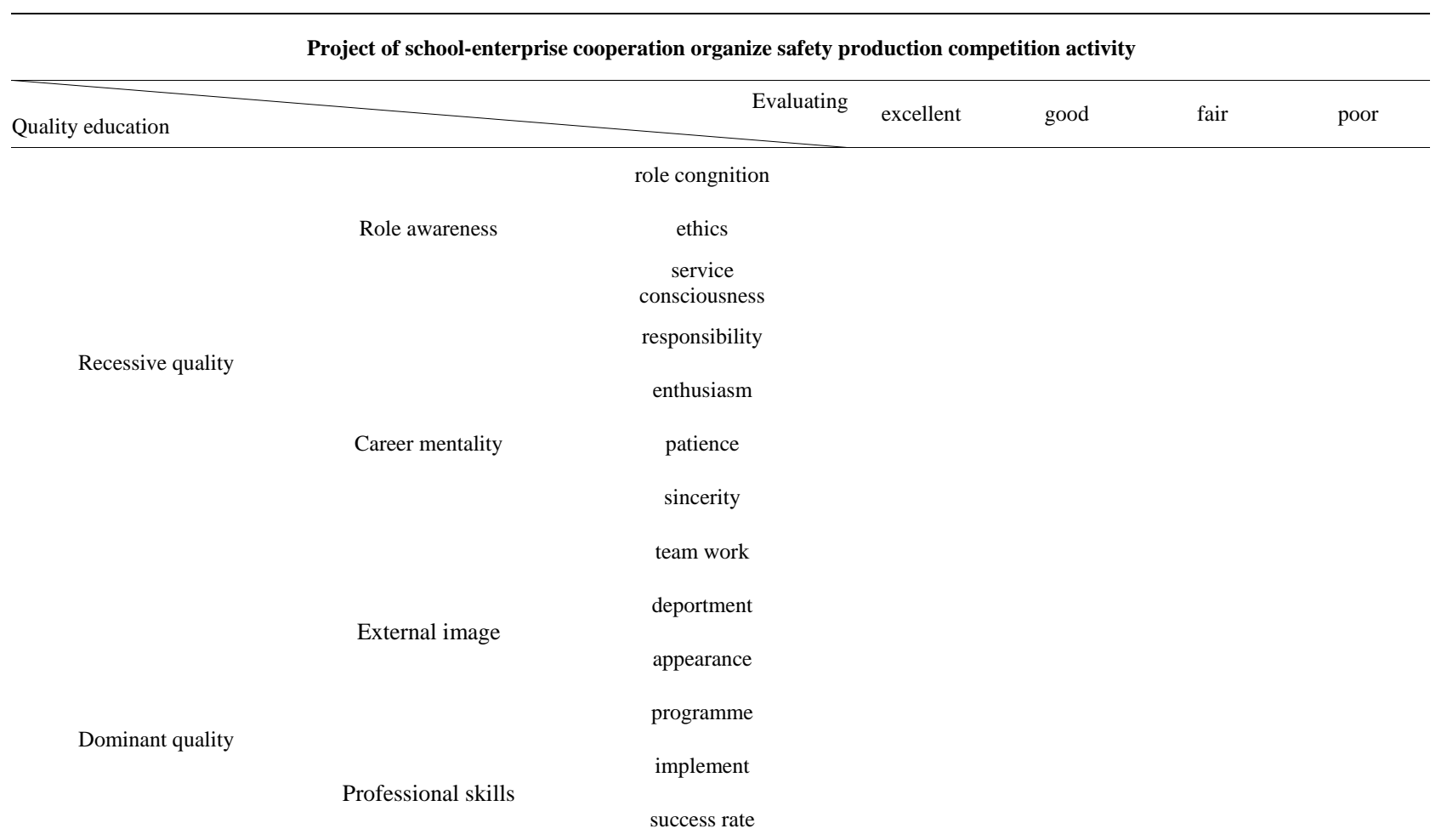




\section{Conclusion}

In this paper, we proposed to apply the general education of international universities, to improve the quality of China higher vocational education. The quality education of CHVE should become a social consensus, and general education makes college students become educated elegant people. Higher vocational education has the support of the country, all of the people involved, there is social consensus, can do more work. In our times, higher vocational quality education reform and development should be based on the idea of general education. The CHVE intrinsic quality education is committed to nurturing and developing students' talent and creating applicable knowledge and skills to support social and economic advancement.

\section{Acknowledgements}

This work was supported by the Jiangsu Overseas Research \& Training Program for University Prominent Young \& Middle aged Teachers \& Presidents.

\section{REFERENCES}

Ministry of Education of China (2010). Higher Vocational Education Annual Report. Beijing: Ministry of Education of China.

Lai, Y. B., \& Wei, Y. Q. (2011). The high-speed constructional teaching materials of higher vocational education should be taking the road of development adaptability with Chinese characteristics. Proceedings of 2011 the Conference on Information Technology and Education Teaching. Wuhan: Scientific Research Publishing, 22002203.

Lai, Y. B. (2010). International teaching reform and practice of engi- neering curriculum of China higher vocational education. $2010 \mathrm{In}$ ternational Conference on Education and Sports Education, 85-87.

Van Dijk, L. A., \& Van Den Berg, G. C. (2001). Interactive lectures in engineering education. European Journal of Engineering Education, 26, 15-28. doi:10.1080/03043790123124

Chen, X. M. (2006). Related concepts discriminating of general education. Higher Education Research, 3, 64-68.

Schneider, C. G. (2012). Liberal education and general education: Education 21st century students for a world shared in common. General Education and University Curriculum Reform: An International Conference in Hong Kong. Hong Kong, June 2012.

Jiao, Z. Y., \& Lai, Y. B. (2010). The values deconstruction of Peopleoriented contemporary education (Example of Nanyang Polytechnic University). 2010 International Conference on Education and Sports Education, 311-314.

European Commission (2008). Proposal for a decision of the European Parliament and of the Council concerning the European Year of Creativity and Innovation (2009). Brussels: European Commission.

Nielsen, K. (2002). The concept of tacit knowledge-A critique. Outlines, 2, 3-17.

Newman, M. J. (2005). Problem based learning: An introduction and overview of the key features of the approach. Journal of Veterinary, 32, $12-20$.

Leon, P. G. B., Mann, L., \& Pirola-Merlo, A. (2001). The innovation imperative: The relationships between team climate, innovation, and performance in research and development teams. Organisational Behavior, 32, 55-73.

Lai, Y. B. (2010). Higher vocational engineering education instructional reform and evaluating design. 2010 Third International Conference on Education Technology and Training, 8-10.

Soto, O. D. (2010). Teacher change in the context of a proof-centered professional development. Ph.D. Thesis, San Diego: University of California.

Wilson, D. H. (2010). Vocational education in high school: A future outlook. Ph.D. Thesis, Minnesota: Capella University. 